\title{
Innovative Development of Student Skills in Raw Materials Engineering Programs
}

\begin{abstract}
J. A. Ramírez Masferrer ${ }^{1}$, J. Herrera Herbert ${ }^{2}$, P. Kindelan Echevarría ${ }^{3}$ 1 Universidad Politécnica de Madrid - UPM (Technical University of Madrid). Department of Civil Engineering, Construction and Transportation. Higher Technical School of Civil Engineering. C/ Alfonso XII no 3 y 5, 28014 Madrid, Spain (j.ramirez@upm.es) ORCID 00000002-0752-9367; ²Universidad Politécnica de Madrid - UPM (Technical University of Madrid). Department of Mining and Geological Engineering. Higher Technical School of Mining and Energy Engineering. C/ Rios Rosas 21, 28003 Madrid, Spain (juan.herrera@upm.es) ORCID 0000-0002-7656-1707; ${ }^{3}$ Universidad Politécnica de Madrid - UPM (Technical University of Madrid). Department of Ligüistics Applied to Science and Technology. Higher Technical School of Mining and Energy Engineering. C/ Rios Rosas 21, 28003 Madrid, Spain (kmanga_009@yahoo.es) ORCID 0000-0002-2555-5956
\end{abstract}

\begin{abstract}
The CDIO Initiative (Conceive, Design, Implement, Operate), successfully adopted in those engineering disciplines where the final result is the design and engineering of an innovative product, had not achieved such penetration, however, in other areas such as mining, metallurgy, or civil engineering where conception, design, and implementation do not result in a product, but in a complex process or system (e.g., mining extraction). Since 2015, financed with funds from the European Union, different projects have been developed to implement this methodology in these areas, which have continued later with the universities' own funds. The objective of this work is to show one of these projects of the educational innovation group "Innovatio Educativa Tertio Millenio" of the Technical University of Madrid during the past academic years 2019-2020 and 2020-2021, working with two specific techniques such as active learning and design thinking. By making students solve real problems and come up with realistic solutions, they worked on key competencies and could experiment without fear of failure.
\end{abstract}

Author Keywords. CDIO, Adaptative Learning, Project-based Learning, Experimental Learning.

Type: Research Article

$\partial$ Open Access $\square$ Peer Reviewed $@$ (i) CC BY

\section{Introduction}

"Behind every innovative idea is an engineer" (NES Fircroft 2021). This sentence shows how knowledge and skills are the two axles on which the future generation of engineers are called upon to be properly trained in their careers. Indeed, engineering education of the $21^{\text {st }}$ century needs to embrace specific training of students in both disciplinary knowledge of engineering principles applied to real industrial problems along with the acquisition of a series of 'skills and competencies' that the business world demands to meet the challenges of the knowledge economy in our era.

The Royal Academy of Engineering defined in 2007 two areas as the main co-existing facets in the role of the engineer in the current business world: Technical understanding and enabling skills. In the first one, a sound knowledge of disciplinary fundamentals and the ability to apply theory into practice stand out; in the second one, a set of skills that allow engineers to work in a business environment must be sought (e.g. creativity, innovation, leadership) (The Royal Academy of Engineering 2007, 4). Indeed, engineering students need also other skills that are 
not just the specific 'technical skills' of their field, traditionally taught and acquired in engineering degrees. Industry and business highlight the fact that the success of an engineer no longer lies in their technical knowledge and expertise, but in other competencies like communication and persuasion, the ability to lead a team and/or work as part of a team, and the capacity to understand forces of a social, economic, political, cultural and human character that affect decisions in the engineering world (Shuman, Besterfield-Sacre, and McGourty $2005,43)$. It is this voice coming from the industry environment that establishes the main requirements to achieve a higher quality in the education of engineers. These requirements can be summarised in: active learning based on simulations and projects; introduction of mathematical and scientific concepts in the context of application; a close interaction with the business world; mastery of information and communication technologies; and finally the emerging role of the teacher as mentor and guide rather than as transmitter of knowledge (Prados 1997, 69).

In the education context, these aspects become a reality by bringing into the engineering curriculum the practical dimension of the studies, the training of students in skills that enhance values, attitudes, and relations with people, and finally a greater interaction with situations and agents actively operating in the labour market (Kindelán and Martín 2008, 734). As the American Board of Engineering Education recommended for a curriculum reform two decades ago: An "early exposure to 'real' engineering" (Shuman, Besterfield-Sacre, and McGourty 2005, 42).

This is where the CDIO initiative came as an innovative educational framework as its main goal is to produce the next generation of engineers based on these pillars. As established in the CDIO syllabus, the education provided to engineering students now highlights the "engineering fundamentals set in the context of Conceiving - Designing - Implementing Operating (CDIO) real-world systems and products" (see http://www.cdio.org/). Engineering education in this perspective involves a new vision which has resulted in the creation of a new syllabus for engineering programs devised by industry and educators in 2001 (version 1), starting from the definition of the essential functions and characteristics of an engineer in our age: "conceive-design-implement-operate complex value-added engineering systems in a modern team-based environment to create systems and products, and are mature and thoughtful individuals" (CDIO vision; http://www.cdio.org/). The new syllabus emphasizes the knowledge, skills, and attitudes that graduating engineers should possess among which creativeness and innovation are highlighted as value-added abilities in the workforce.

Because this initiative mainly started in the areas of aerospace, applied physics, electrical engineering, and mechanical engineering, other branches in the engineering curriculum were drawn into the CDIO initiative at a later stage. In 2016, EIT Raw Materials started funding a project to apply the CDIO methodology to education in Engineering in the raw materials sector.

EIT Raw Materials is a Knowledge and Innovation Community, or KIC, of the European Institute of Innovation and Technology - EIT, an independent body of the EU targeted toward strengthening Europe's innovation capacity (EIT Raw Materials 2021). In 2015, EIT Raw Materials was founded "to ensure access to, supply with and sustainable use of raw materials" (Clausen et al. 2018), and it is participated by more than 120 European partners from leading industries, universities, and research institutions from more than 20 EU countries (EIT Raw Materials 2021), being the largest consortium in the raw materials sector worldwide. The Raw Materials Academy is the overarching brand of all the educational activities of EIT Raw Materials (2021). It fosters new ways of learning and teaching by connecting academia, 
industry, and research organizations "with a special focus on the strengthening of innovation and entrepreneurship in the whole raw material chain" (Herrera Herbert et al. 2017, 2).

\section{The Application of CDIO Principles in the Field of Mining Education}

Like other industries, the mining sector continually seeks ways to improve learning processes that advance its competitiveness and profitability. cost-effectiveness (Herrera Herbert 2019). In the 21st century, mining is driven by the digital revolution (Mining Global 2020), which implies the irruption of new technologies and the need for a highly-skilled workforce "with the ability to perform several tasks through automated and remote-controlled operations and monitoring" (Herrera Herbert and Ramirez Masferrer 2019). This implies the training of mining engineers in a diverse skill set as well as a deep disciplinary knowledge, an objective that becomes a challenge for present-day mining engineering education, which can no longer be addressed with traditional teaching and learning approaches of the past. The real challenge is that education programs become really close to industry - acting as allies - in the resolution of complex and real-life problems and maintain a strong liaison with the research world. The introduction of new methodologies and the perspective on the raw materials value chain poses the question of adapting the programs to a more intelligent raw materials industry (Herrera Herbert and Ramirez Masferrer 2019).

Four key skills areas have been identified in the mining industry for the future workforce: operating practices and technology; talent and leadership; partnership with key stakeholders; and governance. The CDIO Initiative has demonstrated that the implementation of such skills in technical programs and courses is highly effective and viable (Herrera Herbert and Ramirez Masferrer 2019).

The result of this approach is the training of engineers as professionals "that are broad and holistic and have a deep understanding of specific aspects of the value chain and a good understanding of the Raw Materials value chain and a mindset for innovation, entrepreneurship, and sustainability" (Herrera Herbert and Ramirez Masferrer 2019, 3443).

As indicated above, EIT Raw Materials started supporting in 2016 the implementation of CDIO methodology in primary resources linked programs (Herrera Herbert et al. 2017). The Technical University of Madrid was one of the universities that participated in the European Project 'CDIO I' (2016-17) "Implementation of Conceive, Design, Implement and Operate in the Raw materials sector" as a response to the need for updated practices in education in the field of raw materials through the identification of opportunities for improvement, the introduction of modifications in the programs and the training of teachers. This first initiative was followed by another Project "CDIO II - Implementing CDIO in Raw Materials Sector" (2018-2020), with the development of specific actions (activities) carried out in concrete subjects, like Mine Ventilation, Mine Planning, and Design, Rock Mechanics, among others, and that also funded by EIT Raw Materials.

CDIO II project was implemented by a consortium that joined five universities (Chalmers University of Technology, Lulea University of Technology, Technical University of Madrid, University of Limerick, and RWTH Aachen University), which were all CDIO partners, as well as one industry partner (LKAB) and RISE, the Research Institutes of Sweden. It specifically aimed to drive change from traditional educational models towards "industry-driven education in raw materials incorporating CDIO principles" (Sörensen et al. 2019).

Mining engineering has a major role in 'raw materials' education and should, therefore, remain competitive adjusting to technological changes and current industry requirements. Introducing CDIO principles in mining engineering programs leads to a continuous 
improvement of education and a transformation of the teaching paradigm in this field. With the experience acquired in the projects financed by EIT Raw Materials for the implementation of the CDIO methodology in mining education, a third education innovation project, on a smaller scale, began to be developed by an "educational innovation group" from Universidad Politécnica de Madrid - UPM (Technical University of Madrid) called 'Innovatio Educativa Tertio Millennio' (IETM), created in 2000 and formally recognised in 2009 by the UPM's ViceRectorate for Academic Affairs and Strategic Planning. This group set out to boost the research work of lecturers in the educational innovative area as well as to develop new teaching techniques and practices in the field of mining and civil engineering (also including other study fields) intending to adapt teaching to European Higher Education standards.

This paper aims to show how lecturers of this group are bringing to reality - to their teaching practice - the CDIO initiative in the context of mining engineering as well as civil engineering in the last two academic years (2019-2020 and 2020-2021) by showing the work at the Higher Technical School of Mining and Energy Engineering to introduce the CDIO methodology into specific subjects of the 'MSc in Mining Engineering' program and the work the Higher Technical School of Civil Engineering to also implement the CDIO initiative in this other branch.

\section{Application of CDIO: Proposals that Become Real}

There are two teaching situations where 'Tertio Millenio' lecturers are implementing CDIO: The first one in the MSc in Mining Engineering program and the second one in the subject of 'Construction Machinery' in the degree of BSc in Civil Engineering.

From 2019 to the present, the techniques used to teach these subjects are the following:

- Challenge-based learning and design thinking: What is pursued here is making students see the creative and inventive process as a challenge and at the same time enhance their ability to persuade the teacher that their design or proposal is viable and it works.

- Research-based learning: The main aim here is to make students investigate the technological and economic factors, i.e. the possibilities of implementing the idea technically-if the 'idea' is feasible - and the cost of bringing the idea to the real world.

These techniques help students enhance and expand their knowledge by putting it into practice and in this way see that it is useful in real-life contexts.

\subsection{First case example: Mining Engineering subject on Mine Ventilation}

In the case of 'Mine Ventilation' in the MSc in Mining Engineering program, students are given a case study. They go with the teacher inside the "Marcelo Jorissen Mine", which is a reproduction of an old underground coal mine built at the beginning of the 1960's and located in the courtyard of the School. The problem statement they are given is one problematic situation they have to resolve.

The students choose the problem among different issues addressing the question of ventilation in the mine and the teacher just gives them some guidelines to develop the solution so that they go through the different stages of 'Conceive-Design-Implement-Operate' to work out a realistic solution to the problem. The first step is to collect all the maps and information about this old mine of the School and then check that all measurements of the mine are correct and correspond to its actual dimensions. This should be carried out as if the exercise was for a real-life project with a firm of engineers. 


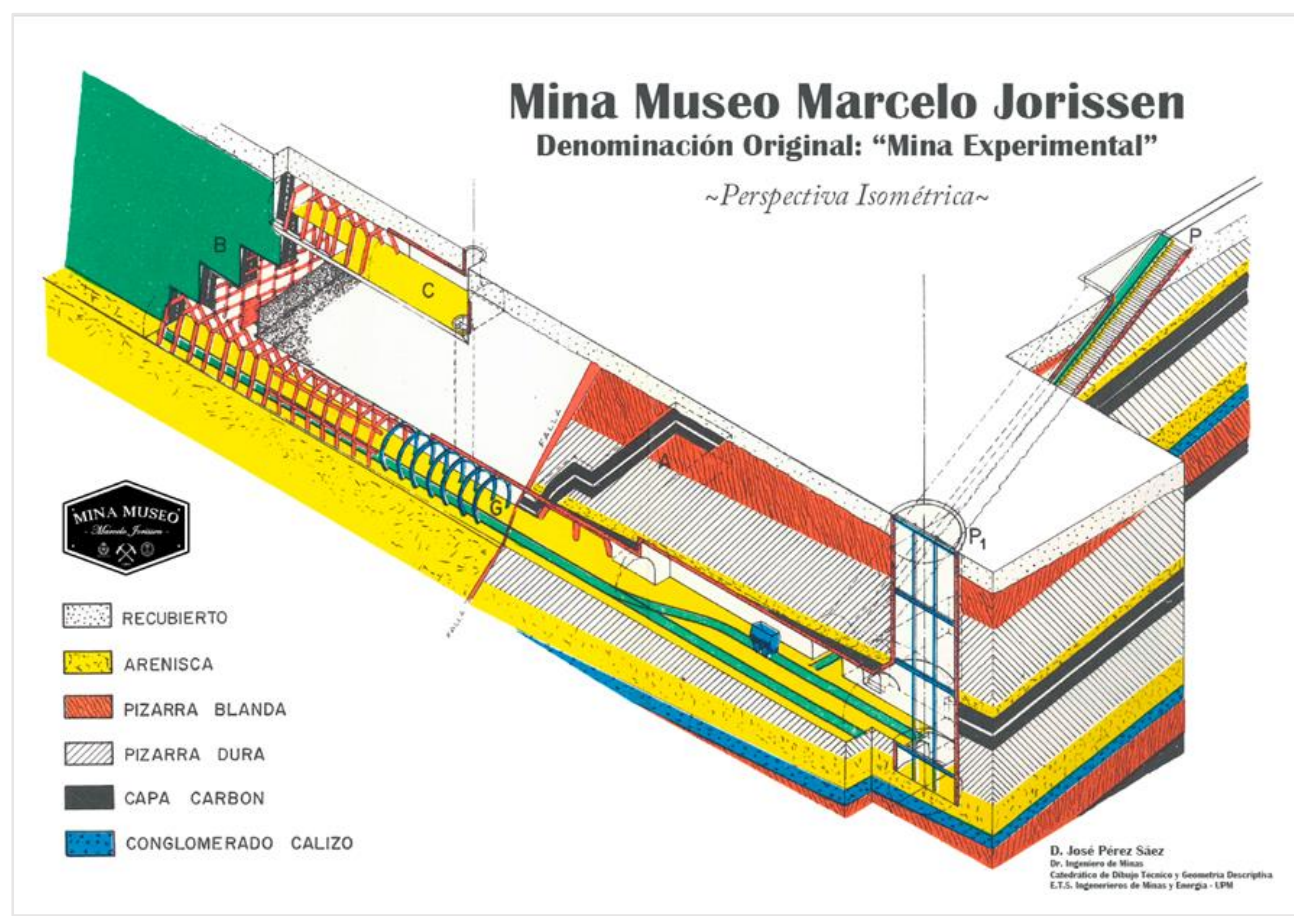

Figure 1: Schematic view of the 'Marcelo Jorissen Mine'

Then, each group must: A) Become acquainted with the problems posed in that context; B) Address and analyse the causes at the roots of the problems; C) Evaluate and propose the most appropriate solution from a technical and economic point of view and constructively. Finally, they will come up with a different strategy. Throughout the entire process, the teacher supervises the work done, corrects it, and orientates students about the skills they have to exercise to arrive at an optimal solution. For example, they learn how to work in a group, develop their spatial ability, practice analytical reasoning to arrive at a logical conclusion by examining the details to fully understand the problem and solve it. Naturally, problem-solving is one of the key competencies that engineering students put into practice, but this time applied to a real-world engineering problem.

The whole purpose is to enable students to identify the gaps in their knowledge of ventilation and constructive features relating to the mining site and the environment and push them to look for various alternatives, to do certain calculations, and consider all the factors and impediments to reach a realistic and achievable solution to the problem posed.

For example, a relevant factor can be the ventilation software applied to the different design and calculation assumptions. An issue of considerable importance is that the mine is regularly open to the public and receives many visits from students of primary and secondary schools. People are allowed to go down and see it, so students must think about additional specific safety measures and find efficient alternatives for an emergency evacuation exit among other issues.

As for impediments, they have to take into account that the building of the School is a protected historical heritage and they cannot make a ventilation shaft wherever they would like. Another obstacle is that the mine is squeezed between two old buildings (it is located in the courtyard that lies in the middle), so there is a limitation in the free space for solutions. Finally, it is in an urban area, not a rural one, so they have to be creative as to the type of solutions they come up with in those circumstances.

They are driven to develop their 'creativity and innovation', take on responsibility for their work, and promote their leadership skills because they have to take on different roles such as 
making decisions as designers, calculators, analysts, etc.; communicating effectively with their teams; and finally, contacting machine suppliers, all of it complying with official regulations and the limitations of the mine. In fact, it means going into detail to see what the implementation of the solution they propose is like. It can be so complex that it might not be feasible, so it demands from them to research the factors that affect the ventilation flow rates, e.g. mine ventilation resistance caused by air friction in the walls and by any other obstacle inside the ventilation circuit. In addition, the reduction of the available space in the drift as a result of the presence of a mine wagon or machine located there. It also demands using design thinking by understanding the context and the users, challenging their own assumptions by 'thinking outside the box', and giving innovative answers to the problem. By applying these techniques to their proposals, they try to persuade the teacher that their solution is viable and that 'it works'.

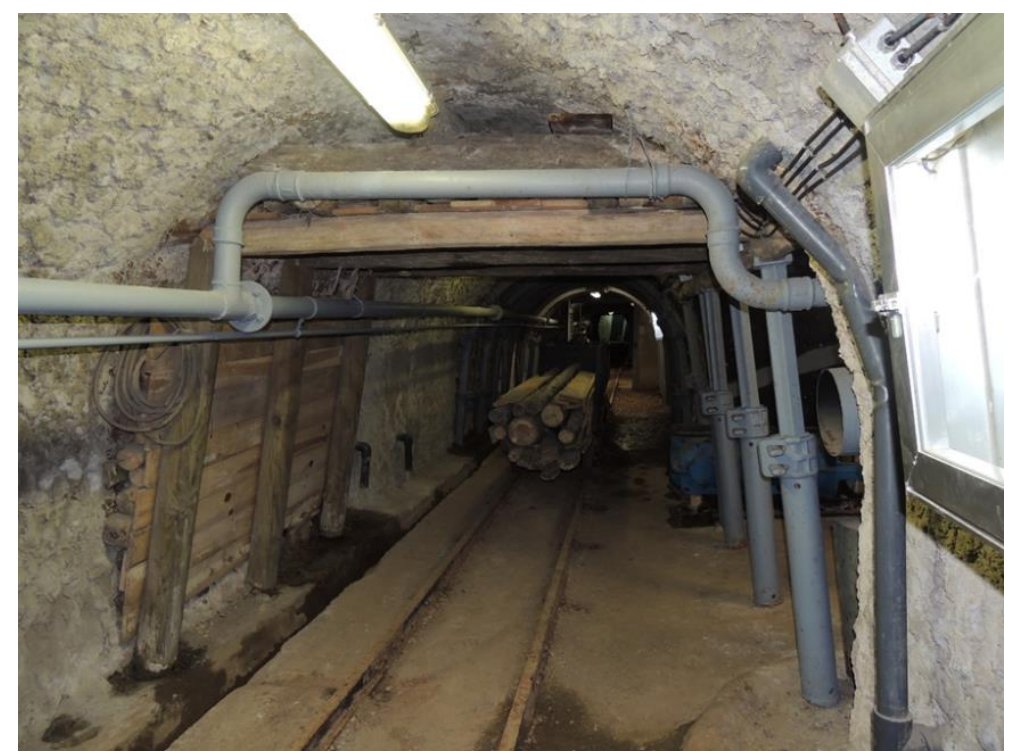

Figure 2: View of the lower drift of 'Marcelo Jorissen Mine' located in the courtyard of the School

The outcome is that they have to work out a conceptual solution that meets the constructive and economic requirements and defend it in front of the teacher and the class. This entails a certain accuracy to reach an optimal solution as well as considering all the challenges that need to be addressed in its implementation.

Finally, students have to submit an elaborate proposal explaining the ideas, discussing the pros and cons in teams in such a way that each team should present the case effectively trying to take the cat to water. This makes evident the degree of coordination they have had among them and their ability to express their ideas clearly, argue their pros and cons, turning these ideas into actions.

This approach to teaching a practical subject with CDIO methodology has allowed putting a real project for the rehabilitation of the mine - carried out by an engineering company - back on track and promoted by the School of Mining and Energy Engineering. The alternatives for implementing this project were already seen and studied by students and the company makes use of their work on the impediments and structural 'bottlenecks' that occur in the process of assessing solutions and giving a final definition, that students were unable to solve (e.g. calculating a particular structure the students did not know existed, incorporating additional limitations not given to them). The result has been very interesting since students' work has helped to put a value on the specific characteristics of the mine. Their analysis can give inspiration to the company when dealing with an essential issue: Accessibility to the mine on 
the part of the public, especially for old, disabled as well as blind people, an issue that students have analyzed.

In short, the application of CDIO has led to strengthening student capacities to conceive, design, implement (in an ideal situation but with a real context) and contribute to building a working solution for that process by viewing how the ventilation circuit in fact should be modified to fit specific requirements.

\subsection{Second case example: Civil Engineering}

In the same academic year 2020-2021, another member of the educational innovation group from the School of Civil Engineering implemented the use of the CDIO methodology to energize learning in the subject of 'Construction Machinery' at his School. This subject is compulsory in the curriculum of Civil Engineering degree and aims the study of machinery and its use in each of the construction procedures.

The problem statement for the CDIO case study required students to create a device or software providing a specific solution to a real need, preferably in the framework of this subject or a significant improvement in the design of a machine or device, e.g. an electric vehicle. However, other interesting topics that address a real problem are also valid, e.g. how to improve mobility in Madrid or coming up with an invention or a completely new design, e.g. devise a tunnel that joins Gibraltar and Morocco.

The motto accompanying the problem definition serves to stimulate their interest and imagination: "The current pandemic is an opportunity to develop the engineering". The teacher leaves open the possibility that students find a topic that they are passionate about and they become confident in their capacity for invention and entrepreneurship. After that, students work by themselves on the problem they have chosen to solve for a month. Usually, they get together in groups of four and they receive information and advice from the teacher, although he strongly endorses the students' view, without imposing any criteria, only intervening in the event of errors.

In the academic year 2019-2020, the groups first presented their proposals orally for 5 minutes in class (it was a class of 103 students out of 188 students enrolled) and 26 groups did the exercise. They were given both feedback and a report showing the strengths and weaknesses of the proposal. Following this assessment, they continued with the same topic or they changed the topic if it was not in tune with the goals set out in the problem statement, that is to say:

1) Solutions that do not follow the basic principles of Physics, e.g. the underground gets started just with its braking energy.

2) Proposals that raise existing solutions, e.g. a camera installed in vehicles to facilitate certain maneuvers like a rearview camera.

The solutions should be a technological innovation in engineering.

Throughout this process, students are evaluated not only by the result but also for their ability to develop and understand the work to be done, the capacity to work in a group, and the effort to reach the solution. Sometimes, though, their proposals lacked one of the main stages: For example, one of them is "A tunnel between Gibraltar and Morocco" that cannot be implemented; however, they can build a functional prototype that serves to bring together what the students have learned. This is the case of a student who proposed a software solution to calculate counterweights of a crane and the resistance of each component, i.e. bending moment, compressive and tensile strength. 


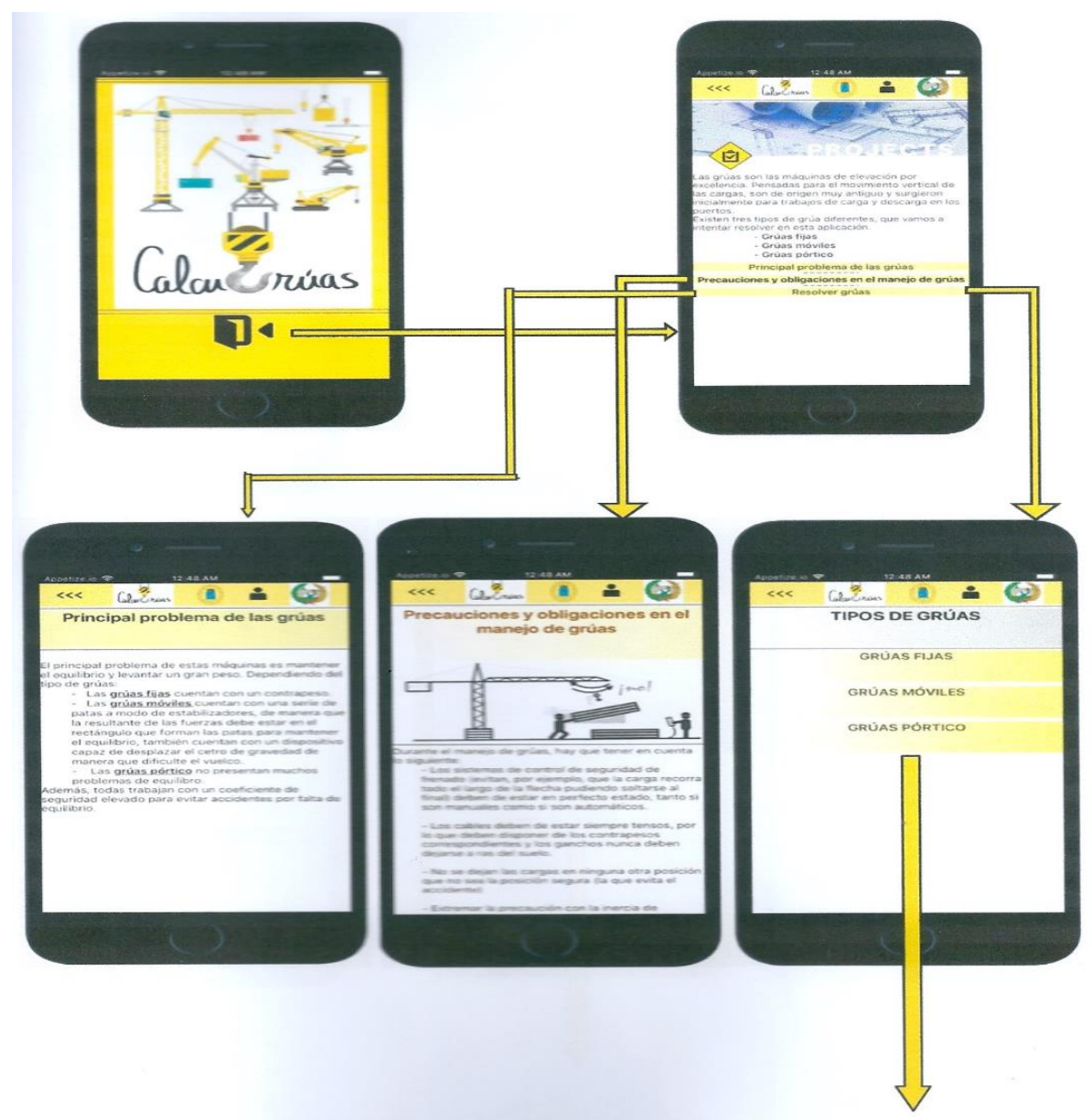

Figure 3: Organizational chart displaying part of the software

In the following academic year 2020-2021, the process was the same but the presentations were done in an open forum in Moodle, where each group explained their proposal in writing (a PDF document) and received the feedback through the forum. The difference between the two academic years lies in the different format in which students have worked: In 2019-2020, students got together physically to develop their own scale model, working with their own hands and putting a lot of hard work and effort to achieve success; conversely, in 2020-2021, teamwork has been less efficient through online teaching and interaction. Students have developed fewer scale models and prototypes. Therefore, we can assume that in a face-toface teaching context, the CDIO methodology seems to work better than in an online training platform.

Application and learning of the CDIO principles were measured by looking at the following elements:

1) If the four CDIO stages had been taken into account in the development of the proposal.

2) If each stage was well developed and data were accurate.

3) If it was an interesting and realistic proposal; its complexity and its viable and valuable solution to solve a real-world problem.

One example is the 'ozone screen located on a surface which is used to avoid airborne disease transmission' (e.g. coronavirus), as shown in Figure 4: 


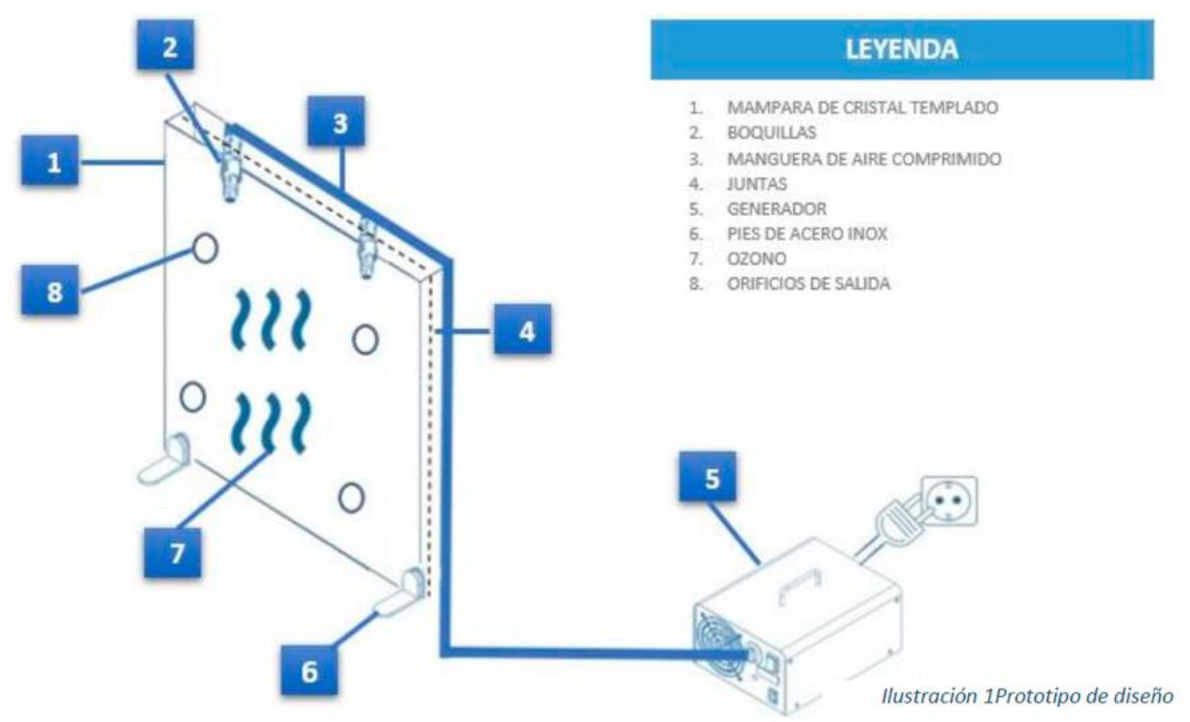

Figure 4: Prototype of the ozone screen

Once the real-scale prototype is produced, the 'operation' would involve its manufacture to see if infections are reduced or eliminated in public places. But what is important here is that the students have put their 'creativeness' to work and they researched screens existing in the market, mechanisms to generate ozone, and also ozone properties to make their own creations 'a real device' that works. Finally, the design of the device made them examine the details of the concept, i.e. size and airflow measurements and the power consumed by the machine, thus resulting in a mechanism that can be manufactured.

\section{Results}

As far as the subject in Mine Ventilation of the MSc in Mining Engineering is concerned, it is noteworthy that the ability of students to work autonomously to develop practical solutions has certainly increased, thus building their self-confidence when it comes to proposing, evaluating, and finding realistic and viable solutions to the problems. The most valuable result of this experience is their interest in finding new creative solutions despite their initial fear and misgivings. We hope this will result in improving student performance and their level of knowledge of the subject.

As for the case of the experiences with students of Civil Engineering, it was observed that many students did not complete the first submission of their proposal in the academic year 2020-2021. Only five groups did and six groups did not even complete any of the stages. However, in the second submission, nearly all groups managed to complete the stages (17 out of 20 groups), as shown in Figure 5:

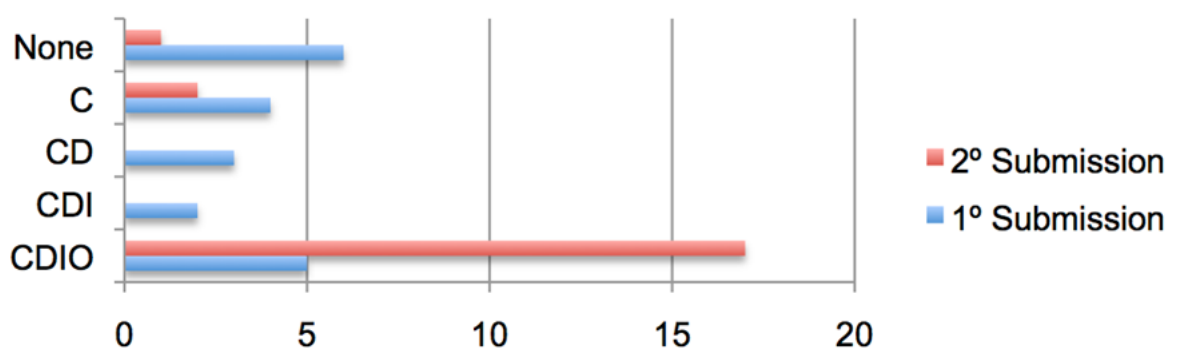

Figure 5: 2020/2021: CDIO stages completed in each group

Likewise, seven groups were able to finish a functional scale model and the rest of the groups built a scale model, used computer programs, or devised interesting solutions in a programing language, as can be seen in Figure 6: 


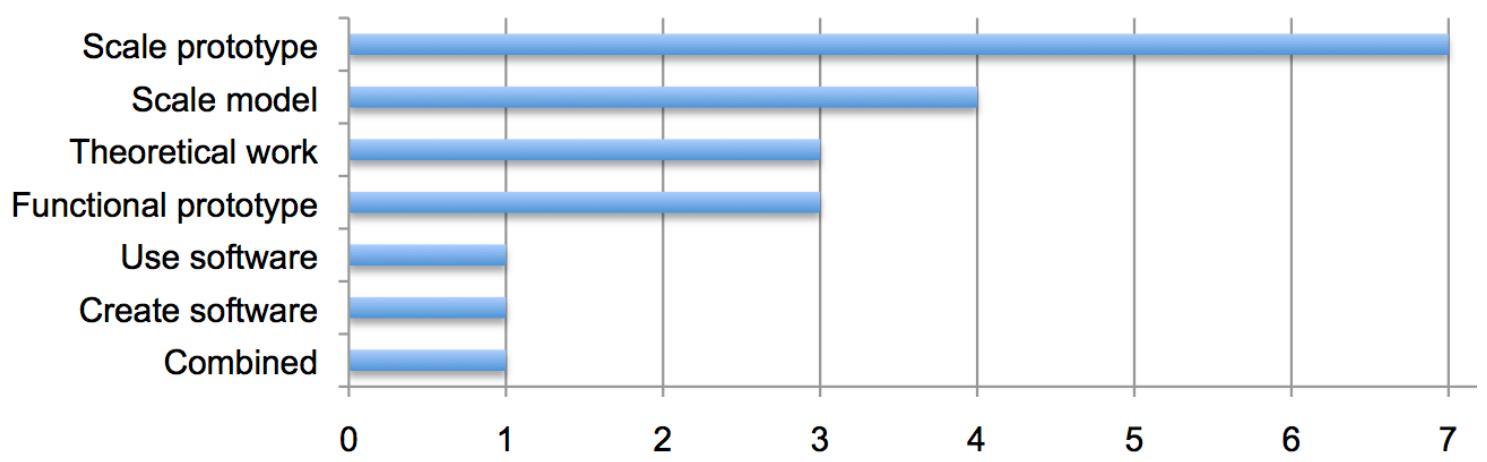

Figure 6: Types of solutions submitted by each group of students

Overall, more than $90 \%$ of proposals were able to separate appropriately each stage Conceive, Design, Implement, Operate - although the last two stages were not developed in full in only three out of the twenty assignments submitted. After analysing the reason for this, it can be concluded that normally this is because a fully functional prototype is not constructed. There is no financial support for this type of work and students are not asked to use their own resources. With these limitations in mind, it is very difficult to 'implement and operate' prototypes, even if some students were able to develop a few interesting prototypes made with recycled waste material.

\section{Conclusion}

Both in the cases in Mining Engineering and Civil Engineering, one of the major impacts of this experience has been that applying the fundamentals of the CDIO methodology has made students become aware of conceptual errors, for example, some basic Physics errors like contradicting thermodynamic principles.

However, the greatest impact observed was that the main concepts explained in theoretical themes were best understood after students had applied these concepts to their proposals or after watching other groups' presentations explaining them.

In the two experiences outlined in this paper, where mining engineering and civil engineering students have been working under different conditions for the last two years, it has been possible to develop a way between the educational project and the standard project in the world of engineering. We need to verify these positive results as we are just seeing they show an increase in students' learning. What is true is that this learning raises student interest and commitment to developing real-life projects in the midst of an 'artificial academic environment'.

Finally, the experiences outlined in this paper are just carried out by voluntary teachers at two Schools of the UPM and are not integrated into a generalised engineering curriculum. It is expected that through the implementation of CDIO principles and practices in these and other courses offered in the UPM, these isolated initiatives can ultimately result in an engineering study plan based on CDIO methodologies.

\section{References}

Clausen, E., A. C. Herz, A. M. Sörensen, E. Hulthén, P. Papadopoulou, A. Binder, J. H. Herbert, D. Tanner, and M. Försth. 2018. "Rethinking Mining Engineering Education Implementation of Conceive - Design - Implement - Operate (CDIO $\left.{ }^{\mathrm{TM}}\right)$ ". Mining Report Glückauf 154, no. 5: 427-34. https://mining-report.de/english/mining-engineeringeducation-conceive-design-implement-operate-cdio/.

EIT Raw Materials. 2021. "EIT Raw Materials". https://eitrawmaterials.eu/. 
Herrera Herbert, J. 2019. "The conception of an Innovative Lab for Education for Mining Technology Education". In INTED2019 Proceedings: 13th International Technology, Education and Development Conference, 2450-58. https://doi.org/10.21125/inted.2019.0674.

Herrera Herbert, J., and J. A. Ramirez Masferrer. 2019. "Implementation of conceive-DesignImplement-Operate in mining engineering education programs". In INTED2019 Proceedings: 13th International Technology, Education and Development Conference, 3440-47. https://doi.org/10.21125/inted.2019.0891.

Herrera Herbert, J., C. Edelbro, E. Hulthén, K. Bhadani, E. Clausen, D. Tanner, K. Jonsson, S. Bealieu, A. Kamp, and M. Försth. 2017. "Implementation of CDIO initiative in new European education programs in raw materials". In EDULEARN17 Proceedings: 9th International Conference on Education and New Learning Technologies, 6518-26. https://doi.org/10.21125/edulearn.2017.2482.

Kindelán, M. P., and A. M. Martín. 2008. "Engineers of the twenty-first century: The importance of Communication and strategic training in the engineers' educational and professional spheres". Arbor: Ciencia, pensamiento y cultura CLXXXIV, no. 732 (july-august): 731-42. https://doi.org/10.3989/arbor.2008.i732.218.

Mining Global. 2020. Mining innovations: 3 trends we'll see in the future. https://miningglobal.com/technology/mining-innovations-3-trends-well-see-future.

NES Fircroft. 2021. "An Engineer's mindset: Creativity in engineering". https://www.nesfircroft.com/blog/2021/09/an-engineers-mindset-creativity-inengineering.

Prados, J. W. 1997. "The Editor's Page: Engineering Criteria 2000-A Change Agent for Engineering Education". Journal of Engineering Education 86, no. 2: 69-70.

Shuman, L. J., M. Besterfield-Sacre, and J. McGourty. 2005. "The ABET "Professional Skills" Can they be taught? Can they be assessed?". Journal of Engineering Education 94, no. 1: 41-55. https://doi.org/10.1002/j.2168-9830.2005.tb00828.x.

Sörensen, A., M. Getz, A. Herz, E. Clausen, E. Hulthén, P. Papadopoulou, D. Tanner, and J. Herrera Herbert. 2019. "An international network of innovative educational labs in mining engineering". In The 15th International CDIO Conference: Proceedings - Full Papers, 48998. https://doi.org/10.7146/aul.347.

The Royal Academy of Engineering. 2007. Educating Engineers for the $21^{\text {st }}$ century. The Royal Academy of Engineering. https://www.raeng.org.uk/publications/reports/educatingengineers-21st-century. 